\title{
Modelagem da Perda Superficial de Solo para Cenários de Agricultura e Pastagem na Região Metropolitana de Goiânia
}

\author{
Modeling of surface soil loss for agriculture and pasture scenarios for the \\ metropolitan region of Goiânia, Brazil
}

\section{Gabriella Santos Arruda de Lima ${ }^{1}$, Nilson Clementino Ferreira ${ }^{2}$, Manuel Eduardo Ferreira ${ }^{3}$}

Recebido em dezembro de 2017.

Aprovado em outubro de 2018.

\begin{abstract}
RESUMO
A determinação da perda superficial dos solos representa uma informação importante no planejamento territorial. O processo de erosão laminar advém de agentes naturais, como a topografia, a chuva e a tipologia de solos, intensificados pela ação antrópica. Na região metropolitana de Goiânia (RMG), tais processos são agravados pela retirada da cobertura vegetal nativa para expansão urbana e implantação de pastagens e culturas agrícolas. A Equação Universal de Perda dos Solos (USLE), aplicada em Sistemas de Informações Geográficas (SIG), permite estimar a erosão em variadas condições e cenários de uso da terra. Neste artigo objetivou-se determinar e espacializar a susceptibilidade erosiva para o atual uso da terra e também para diferentes cenários de ocupação antrópica, visando prognosticar o quanto a conversão deste ativo ambiental pode colaborar para a ocorrência de erosão, e em quais intensidades. Considerando toda a área da região metropolitana de Goiânia, foram simulados os seguintes cenários: Atual (todas as classes de uso), Pastagem e Agricultura. A susceptibilidade erosiva para Pastagem aumentou em 51\%, e em 110\% para Agricultura, em comparação com o cenário Atual. Os resultados obtidos também reforçam que a conversão dos passivos ambientais resulta num significativo aumento da susceptibilidade erosiva na RMG.
\end{abstract}

PALAVRAS-CHAVE: Erosão Laminar. USLE. Antropização. Desmatamento. Cerrado.

\footnotetext{
${ }^{1}$ Universidade Federal de Goiás - UFG, Campus Samambaia (Campus II) CEP 74690-900 - Caixa Postal: 131 - Goiânia - GO, Brasil. Programa de Pós-graduação em Ciências Ambientais, Brasil. Email: gabibela_l@hotmail.com

2Universidade Federal de Goiás - UFG, Campus Samambaia (Campus II) CEP 74690-900 - Caixa Postal: 131 - Goiânia - GO, Brasil. Programa de Pós-graduação em Ciências Ambientais, Brasil. Email: nclferreira@gmail.com.

${ }^{3}$ Universidade Federal de Goiás - UFG, Campus Samambaia (Campus II) CEP 74690-900 - Caixa Postal: 131 - Goiânia - GO, Brasil. Programa de Pós-graduação em Ciências Ambientais, Brasil. Email: mferreira.geo@gmail.com.
} 


\begin{abstract}
The determination of surface loss of soils represents an important information in territorial planning. The process of laminar erosion comes from natural agents, such as topography, rainfall and soil typology, intensified by anthropic action. In the metropolitan region of Goiânia (RMG), these processes are exacerbated by the withdrawal of native vegetation cover for urban expansion and the implantation of pastures and agricultural crops. The Universal Soil Loss Equation (USLE), applied in Geographical Information Systems (GIS), allows estimating erosion in a variety of land use scenarios and conditions. In this article, we aimed to determine and spatialize the erosive susceptibility to the current land use and to different scenarios of anthropic occupation, aiming to predict how much the conversion of this environmental asset can contribute to the occurrence of erosion, and in which intensities. Considering the whole area of the metropolitan region of Goiânia, the following scenarios were simulated: Current (all classes of use), Pasture and Agriculture. Erosive susceptibility to Pasture increased by $51 \%$ and by $110 \%$ for Agriculture, compared to the Current scenario. The results obtained also reinforce that the conversion of the environmental liabilities results in a significant increase of the erosive susceptibility in the RMG.
\end{abstract}

KEYWORDS: Laminar Erosion. USLE. Anthropization. Deforestation. Cerrado.

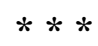

\title{
Introdução
}

O transporte de partículas de solos é normalmente causado pela ação do vento (erosão eólica) e pela água (erosão hídrica); juntos, esses processos podem ocasionar a chamada erosão laminar, que consiste na perda superficial do solo de forma uniforme, ao longo de uma vertente no terreno (BERTONI e LOMBARDI NETO, 1993; BERTONI e LOMBARDI NETO, 2010). Em função de sua localização tropical e dos elevados índices pluviométricos, no Brasil a erosão hídrica é predominante, atuando a partir do impacto das gotas de chuva e arraste de partículas do solo em terrenos sem a cobertura vegetal (PRUSKI, 2009). De acordo com Ranieri et al. (1998), entre os principais fatores que induzem esse processo, estão a erosividade da chuva, a erodibilidade dos solos e as características do relevo, intensificados pelo tipo de ocupação antrópica, sendo esse último fator chamado de erosão antrópica, 
cujo processo pode ser acelerado ou reduzido de acordo com a cobertura e manejo da terra.

O intenso uso da terra no estado de Goiás para a agricultura e pecuária, em muitos casos sem o devido planejamento e práticas conservacionistas, pode contribuir para cenários de insustentabilidade ambiental (FERREIRA et al., 2009). Na região metropolitana de Goiânia (RMG), uma área central no estado constituída por 20 municípios (dentre estes a capital Goiânia), se observa, além do desenvolvimento de atividades agropecuárias e industriais, um intenso processo de urbanização, com marcantes alterações do ambiente natural. Com a mudança do uso da terra, a infiltração de água no solo fica reduzida, aumentando o escoamento superficial, podendo resultar em alagamentos, enchentes e erosões (SILVA, 2015). Além disso, em regiões de grande adensamento urbano, pautados pela impermeabilização do solo, o efeito de ilhas de calor torna-se frequente, com alteração na intensidade pluviométrica (TEZA e BAPTISTA, 2005).

No sentido inverso, a presença de biomassa vegetal (nativa ou não) controla a erosão hídrica, ao permitir a interceptação pluviométrica, reduzir a energia gerada pelo impacto das gotas de chuva na superfície, e possibilitar maior infiltração da água no solo por meio das raízes; todo este processo, por sua vez, reduz o escoamento superficial, diminuindo o arraste das partículas de solo (COOK e DOORNKAMP, 1990).

Nesse estudo, o qual visa medir a perda de solo ocasionada pela erosão laminar, em diferentes cenários de ocupação antrópica na RMG, será adotada a Equação Universal de Perda dos Solos (USLE, na sigla em inglês), proposta por Wischmeier e Smith (1978). Inicialmente calibrada para localidades dos Estados Unidos de forma empírica, esta passou a ser aplicada em mais de cem países (FAO, 1962), frente aos resultados satisfatórios para orientar a conservação dos solos.

Atualmente, a USLE é amplamente utilizada como método de avaliação da perda de solos para locais com características singulares e na tomada de decisão, objetivando a conservação de parcelas agrícolas. Diante 
deste cenário diversos autores (BERTOL e ALMEIDA, 2000; VOLK et al., 2004; BUENO, 2005 GUERRA, 2011) utilizaram a equação para estimar a erosão laminar de forma indireta. Stein et al (2003) realizaram um estudo na bacia do rio Santo Anastácio em São Paulo, Brasil, utilizando um conjunto de informações como o clima, pedologia, geomorfologia e geologia para determinar a suscetibilidade a erosão, essas informações acrescido ao mapeamento de uso e cobertura da terra foram integradas para definir os atuais riscos de erosão da região, objetivando recuperar os danos provocados pela intensa ocupação antrópica da bacia.

Marques et al. (1997) que realizaram um trabalho focado no estudo dos melhores índices para determinação da erosividade da chuva, e para estimar o fator erodibilidade da USLE, para dois solos da região dos Cerrados. Na bacia hidrográfica do rio Vieira, localizada no estado de Minas Gerais os autores Magalhães et al. (2012) observaram que as maiores perdas do solo estão associadas as áreas com solo exposto e recobertas por Argissolos Vermelho Amarelo.

Os fatores que compõe a equação são: índice de erodibilidade do solo, índice de erosividade da chuva, topografia (declividade), uso e cobertura da terra e práticas de manejo. Com atributos determinados separadamente, torna-se possível simular cenários de ocupação para se estabelecer uma adequação ambiental ou mesmo para se medir o impacto da expansão de passivos ambientais, atuando como um importante suporte na tomada de decisão (MACHADO et al., 2003). Junto com a USLE, o Sistema de Informação Geográfica (SIG) é considerado um integrador das informações da Equação utilizada para estimativa de perda de solo, pois permite a espacialização dos dados de forma isolada, bem como uma relação entre as variáveis por meio de uma álgebra de mapas, fornecendo como resultado a localização dos processos erosivos em diferentes gradientes.

A análise da expansão erosiva será analisada no referido trabalho, objetivando indicar o quanto a conversão da cobertura vegetal na RMG, em 
detrimento da expansão da pastagem e da agricultura, pode intensificar a ocorrência de erosão laminar.

\section{2 localização e caracterização da área de estudo}

A Região Metropolitana de Goiânia (RMG) está localizada entre as coordenadas de latitude Sul $16^{\circ} 08^{\prime}$ e $17^{\circ} 12^{\prime}$, e longitude Oeste $49^{\circ} 44^{\prime}$ e $48^{\circ}$ 48'. Composta por vinte municípios, ocupa uma área de $7.315 \mathrm{~km} 2$, atualmente residem na RMG cerca de 2,38 milhões de habitantes, ou $35 \%$ da população de Goiás (IBGE, 2010), sendo a região de maior representatividade demográfica, social e econômica do estado, conforme Figura 1.

Figura 1 - Mapa de uso e cobertura da terra da região metropolitana de Goiânia.

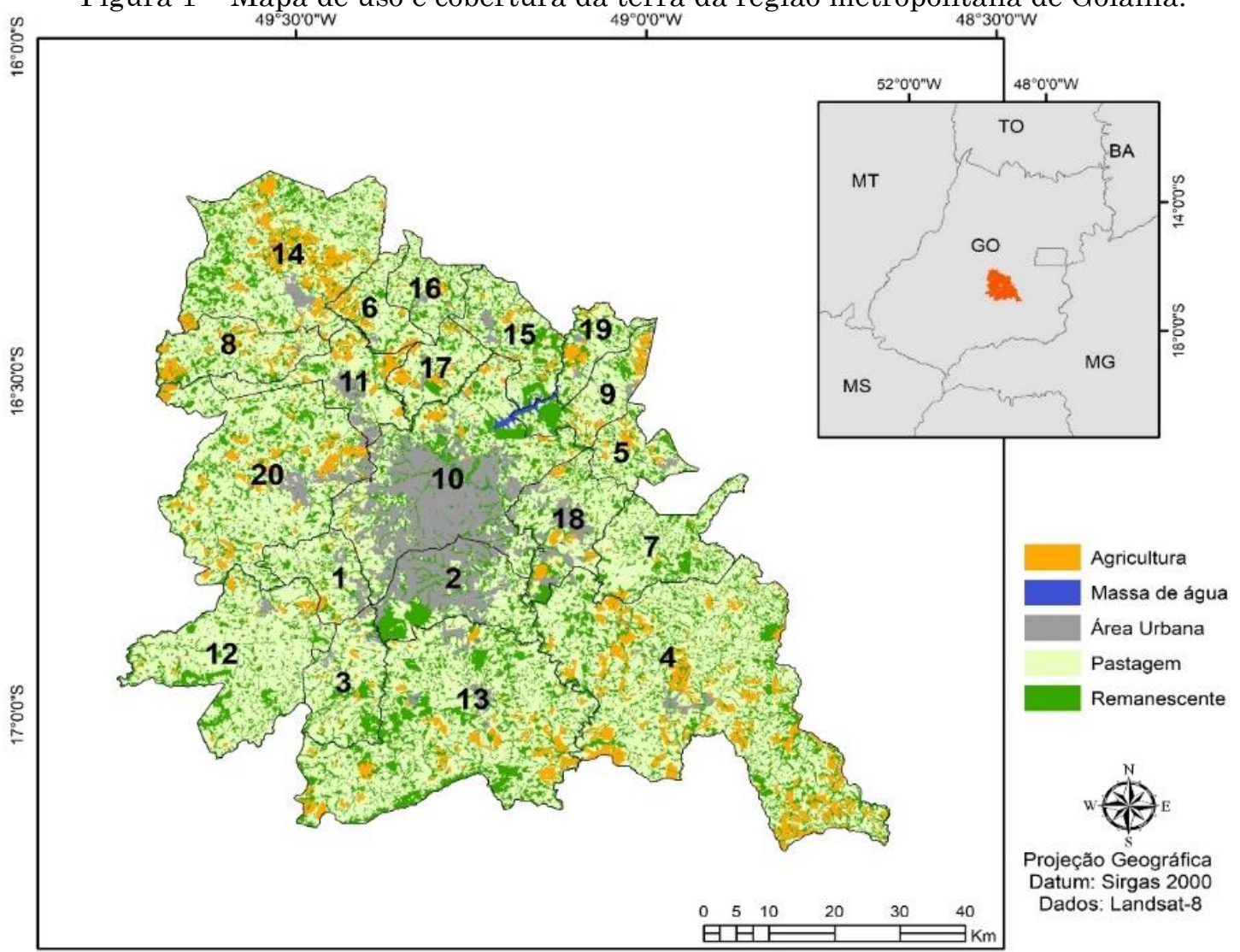

1. Abadia de Goiás

2. Aparecida de Goiânia

3. Aragoiânia

4. Bela Vista de Goiás
5. Bonfinópolis 9. Goianápolis 13. Hidrolândia 17. Santo Antônio de Goiás

6. Brazabrantes 10. Goiânia 14. Inhumas 18. Senador Canedo

7. Caldazinha 11. Goianira 15. Nerópolis 19. Terezópolis de Goiás

8. Caturai 12 . Guapo

16. Nova Veneza 20. Trindade

Fonte: Lima et al. (2017), adaptado pelos autores. 
De acordo com o último mapa de uso e cobertura da terra, apresentado na Figura 1, elaborado por Lima et al. (2017), a maior parte dos municípios encontra-se em processo de antropização avançado, com a predominância da classe de pastagem, seguida pelas áreas urbanizadas, principalmente no município de Goiânia, e pela classe de agricultura (também presente em todos os municípios), mas com predominância ao norte e sudeste da RMG, fechando com a classe de vegetação remanescente, amplamente fragmentada.

Os domínios pedológicos na área de estudo são os Argissolos de textura média e argilosa de ocorrência em relevo ondulado a suavemente ondulado, Cambissolos de textura média e argilosa em relevos ondulado a fortemente ondulado, Gleissolos de textura argilosa em relevo plano a suavemente ondulado, Latossolos de textura argilosa em relevo plano a suavemente ondulado, e Neossolos de textura média e arenosa em relevo fortemente ondulado (EMBRAPA, 1999). O clima da região, segundo a classificação Koeppen, é do tipo Aw, Tropical Úmido, com duas estações bem definidas, seca e chuvosa, na qual nos meses de dezembro e janeiro ocorre a maior concentração pluviométrica, com médias de $270 \mathrm{~mm}$, e no período de maior seca, nos meses de junho, julho e agosto, podendo chegar a $0 \mathrm{~mm}$; a média pluviométrica anual fica em torno de 1600 mm (INMET, 1992).

\section{Materiais e métodos}

A metodologia da Equação Universal de Perda dos Solos (USLE), proposta por Wischmeier e Smith (1978), objetiva determinar o Fator A, a partir da relação entre fatores naturais e antrópicos, resultando na modelagem da perda anual dos solos. Aplicada em um Sistema de Informações Geográficas, a equação permite a espacialização do potencial erosivo, conforme a Equação 1:

$$
A=R . K . L . S . C . P
$$

Sendo, 


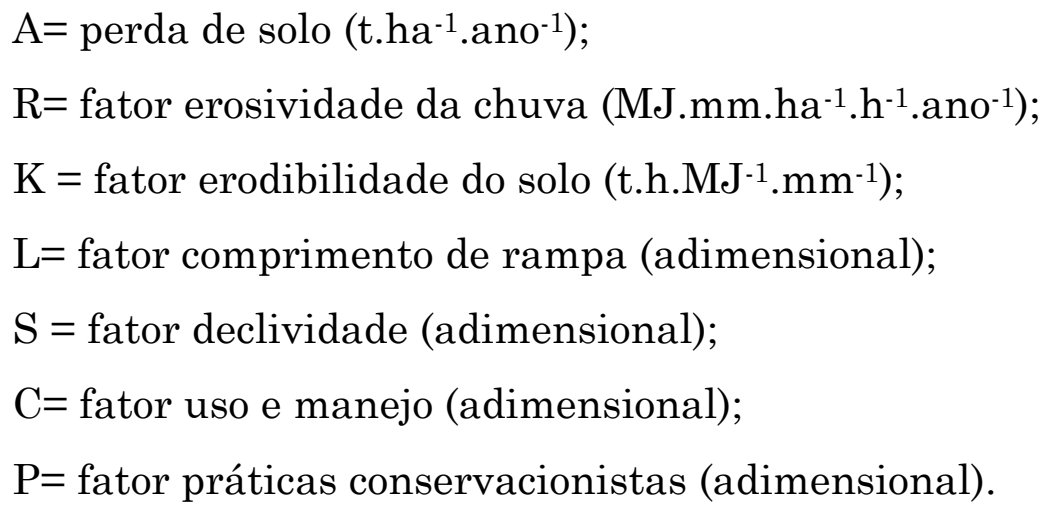

A metodologia foi dividida em duas etapas: (a) obtenção e preparação da base de dados, e (b) determinação de cada um dos fatores, de forma espacializada, variando conforme cada atributo e localidade. As bases de dados referente aos mapas de solos foi adquirida junto ao Sistema Estadual de Geoinformação de Goiás (SIEG), o banco de dados com as informações das amostras de solos para o estado de Goiás é proveniente do Sistema de Informação de Solos Brasileiros (https://www.sisolos.cnptia.embrapa.br/). Quanto aos dados de precipitação o acesso é realizado pela plataforma do CHIRPS (Climate Hazards Group InfraRed Precipitation with Station data) de forma gratuita em (http://chg.geog.ucsb.edu/data/chirps/). O mapa de uso e cobertura da terra foi adquirido a partir do trabalho disponibilizado por Lima et al. (2017).

Os dados adquiridos foram normalizados para o Sistema de Projeção Geográfica e o Datum SIRGAS 2000. Os produtos finais serão apresentados na escala de 1:250.000.

A determinação de cada fator é apresentada a seguir:

\subsection{Fator $\mathrm{R}$}

A erosividade consiste na capacidade potencial da chuva em provocar erosão em um solo sem proteção. $O$ fator $R$ foi calculado por meio do índice de Fournier (1960), proposto por Lombardi Neto e Moldenhauer (1992), na qual 
obtém-se inicialmente a média mensal do índice de erosão e, então, as médias são acumuladas para gerar o fator erosividade, conforme Equação 2 e 3:

$$
R=\sum_{i=1}^{12} \quad E I_{30 i}
$$

Sendo:

$$
E I_{30 i}=67,355\left(\frac{r^{2}}{p}\right)^{0,85}
$$

Onde: $\mathrm{EI}=$ média mensal do índice de erosão (MJ mm ha-1 h-1); $\mathrm{r}=$ precipitação média mensal $(\mathrm{mm}) ; \mathrm{P}=$ precipitação média anual $(\mathrm{mm})$; i= índice de meses; e $\mathrm{R}=$ erosividade.

A precipitação foi obtida por meio dos dados mensais CHIRPS (Climate Hazards Group InfraRed Precipitation with Station data), o qual é um conjunto de dados que incorpora imagens de satélite com estações meteorológicas em solo, gerando séries temporais de precipitação. As imagens geradas abrangem as latitudes de $50^{\circ} \mathrm{S}$ a $50^{\circ} \mathrm{N}$, e todas as longitudes, com série histórica iniciada em 1981 até o presente, e resolução espacial de $0,05^{\circ}$ (aproximadamente $5 \mathrm{~km}$ ).

A partir dos dados CHIRPS, foi gerada uma série histórica de trinta anos (1987 a 2016) de precipitação, sendo realizado a média mensal e a média anual de precipitação para a RMG, visando compor as equações (2 e 3) de erosividade. Os dados produzidos foram recortados para a área de interesse, resultando em um raster composto em média por 72 pixels, os quais deram origem a malha de pontos com $10 \mathrm{~km}$ de distância entre si, tais pontos foram utilizados para realizar a interpolação dos dados gerados, por meio do método Krigagem. Conforme avaliação de desempenho desse método, para espacialização de dados pluviométricos, o mesmo está entre os melhores interpoladores (MELLO et al., 2003; CARVALHO e ASSAD, 2005; WANDERLEY et al., 2012). 


\subsection{Fator K}

Os valores da erodibilidade (fator $\mathrm{K}$ ) foram adquiridos com base na Equação 4, desenvolvida para a região central do Brasil, proposta por Chaves (1996), com dados de entrada provenientes de amostras de solos de todo o estado de Goiás, fornecidos em formato tabular pelo Sistema de Informação de Solos Brasileiros (EMBRAPA, 2014). Assim, os valores adquiridos para o fator $\mathrm{K}$ foram vinculados com as respectivas classes de solos obtidas na escala 1:1.000.000 adquiridas junto ao projeto Radambrasil (2005).

$$
k=\frac{-0,00043(A F+S I L)}{C O+0,000437 A R+0,000863 S I L}
$$

Onde: $\mathrm{K}$ é a erodibilidade do solo (t ha h ha-1 MJ-1 mm-1); AF é a \% de areia fina no solo; SIL é a \% de silte; CO é a \% de carbono orgânico; AR é a \% de areia total no solo.

Os valores de erodibilidade obtidos foram classificados de acordo com Carvalho (1994), conforme Quadro 1:

Quadro1 - Classificação da erodibilidade.

\begin{tabular}{|c|c|}
\hline $\begin{array}{c}\text { Erodibilidade (Fator K) } \\
\text { (t.h.MJ-1.mm-1); }\end{array}$ & $\begin{array}{c}\text { Classes de } \\
\text { interpretação }\end{array}$ \\
\hline$<0,0198$ & Baixa \\
\hline 0,0198 a 0,040 & Média \\
\hline$>0,040$ & Alta \\
\hline \multicolumn{2}{|c|}{ Fonte: Carvalho (1994). }
\end{tabular}

\subsection{Fator LS}

Os fatores $\mathrm{L}$ (comprimento da rampa) e $\mathrm{S}$ (declividade), foram determinados em conjunto utilizando um SIG, dando origem ao fator topográfico da USLE. O fator LS foi obtido a partir do modelo digital de elevação (MDE) da missão SRTM (Shuttle Radar Topography Mission) com 
resolução espacial de aproximadamente 30 metros, projeção geográfica e Datum horizontal WGS84 sendo convertidos para SIRGAS 2000. O SRTM é disponibilizado a partir de 2014 gratuitamente pela United States Geological Survey (USGS) no endereço <https://earthexplorer.usgs.gov/>.

Para cobrir a área de estudo realizou-se um mosaico dos seguintes dados SRTM: (S18W050; S17W050; S17W049; S18W049). O MDE obtido foi processado no software System for Automated Geoscientific Analyses (SAGA), no qual inicialmente obteve-se a declividade do terreno e a área de contribuição, para realização do cálculo do fator topográfico. Para tanto foi utilizado como referência a metodologia desenvolvida por Moore e Burch (1986), conforme a Equação 5.

$$
L S=\left(\frac{A s}{22,13}\right)^{m} x\left(\frac{\operatorname{sen} \theta}{0,896}\right)^{n}
$$

Onde: As é o produto da acumulação de fluxo pelo tamanho da célula (área de contribuição); $\theta$ é o declive em graus; $m$ é o comprimento do ângulo de inclinação; n é o expoente de inclinação; 22,13 é o comprimento padrão da USLE; e 0,0896 é o declive padrão da USLE.

\subsection{Fator C e P}

Os fatores relacionados à ação antrópica, $\mathrm{C}$ (uso e cobertura da terra) e $\mathrm{P}$ (práticas conservacionistas), foram utilizados em conjunto. Para o Fator C, foi empregado o mapeamento de uso e cobertura da terra associado aos respectivos coeficientes de uso da terra propostos por Stein et al. (1987), e também adotados por Baptista (2003), conforme Quadro 2. Para o fator prática conservacionista foi adotada a constante igual a 1, que representa a pior situação de práticas conservacionistas na perda do solo, pois a grande extensão da área impossibilita a obtenção de valores de $\mathrm{P}$ confiáveis e individualizados. 
Quadro 2 - Fator CP em função do uso e ocupação da terra.

\begin{tabular}{|c|c|}
\hline $\begin{array}{c}\text { Uso e ocupação da } \\
\text { terra }\end{array}$ & $\begin{array}{c}\text { Fator CP } \\
\text { (adimensional) }\end{array}$ \\
\hline Agricultura & 0,1200 \\
\hline Água & 0 \\
\hline Área urbana & 0 \\
\hline Vegetação Savânica & 0,0007 \\
\hline Pastagem & 0,0550 \\
\hline
\end{tabular}

Fonte: Stein et. al (1987) adaptado.

O mapa de uso e ocupação da região metropolitana de Goiânia realizado por Lima et al. (2017), foi elaborado a partir de imagens Landsat 8 do sensor OLI do ano de 2015 e 2016, referentes às orbitas-ponto 221-72, 222-71 e 22272. Com o objetivo de realizar um mapeamento em escala superior a 1:100.000, foi realizada uma fusão das bandas multiespectrais, e a banda pancromática deste mesmo sensor, com resolução espacial de 15 metros. Em seguida, tais imagens foram segmentadas no software Spring (versão 5.2.6.1) em polígonos com área mínima de 6,25 ha, procedendo-se com a classificação das imagens. Por fim, foi realizada uma inspeção visual na classificação para a eliminação possíveis inconsistências. Para validação do mapeamento gerado os polígonos classificados equivocadamente foram alterados manualmente (LIMA et al 2017). As classes consideradas foram agricultura, área urbana, vegetação savânica, corpos hídricos e pastagem.

3.5 Cenários de previsão para conversão da vegetação remanescente

Os fatores erosividade (fator R), erodibilidade (fator $\mathrm{K}$ ), topográfico (fator LS), cobertura e uso da terra e práticas conservacionistas (fator CP), a partir da metodologia aplicada, os resultados obtidos foram apresentados em imagens (rasters), sendo cada fator reamostrado para o tamanho do pixel de 30 metros, sendo gerado o mapeamento de cada um destes fatores separadamente. 
De posse destes dados, foram multiplicados os fatores para obtenção da susceptibilidade erosiva espacializada com o cenário "Atual" de uso e ocupação da terra, bem como calculadas as potenciais perdas dos solos para outros dois cenários hipotéticos, o primeiro considerando todas as áreas remanescentes convertidas para agricultura, e o segundo considerando a conversão para a pastagem.

\section{Resultados e discussão}

A utilização do índice EI30 é recorrente na determinação da erosividade tanto em trabalhos clássicos quanto em obras recentes, conforme os autores (LOMBARDI NETO e MOLDENHAUER (1992); NASCIMENTO e CHAVES, 1996; COLODRO et al 2002; BAZZANO et al 2007 MELLO et al 2012) é um índice prático e de grande utilização, resultando em boas estimativas do fator R (erosividade da chuva). Os autores Marques et al. (1997), utilizaram o EI30 para a região dos Cerrados, concluindo que o índice garante a melhor estimativa da erosividade da chuva na região analisada.

Na Figura 2, são apresentados a média de precipitação e o índice de erosividade mensal, observa-se que os meses de maior precipitação, no período analisado (30 anos), foram janeiro e dezembro, contribuindo assim com os maiores valores de erosividade, enquanto junho, julho e agosto foram meses com o menor potencial erosivo. Na figura 3 (A) pode ser visualizado a erosividade calculada, na qual obteve-se os valores médios anuais variando entre 8.157,22 a 8.826,89 MJ mm ha-1 $\mathrm{h}^{-1}$, sendo a média de 8.426,77 MJ mm $\mathrm{ha}^{-1} \mathrm{~h}^{-1}$ classificada como forte nessa região, de acordo com a interpretação proposta por Carvalho (2008). 
Figura 2 - Precipitação e índice de erosividade mensal da região metropolitana de Goiânia (1987 - 2016).



Fonte: Elaborado pelos autores.

RADAMBRASIL et al. (2007) conduziram um estudo para diversas regiões de Minas Gerais, que apresentam uma distribuição pluviométrica anual semelhante à região aqui analisada, e estimaram o valor mínimo de erosividade de 5.000 e máximo de $12.000 \mathrm{MJ} \mathrm{mm} \mathrm{ha-1} \mathrm{h}^{-1}$. Estudos realizados para o centro-oeste brasileiro também sugerem semelhanças, como na região de Goiânia, em que Silva et al. (1997) obtiveram o valor de 8.353,00 MJ mm $\mathrm{ha}^{-1} \mathrm{~h}^{-1}$ de erosividade média anual. Em estudos realizados por Dedecek (1988) e Morais et al. (1991) para Brasília e sudoeste do Mato Grosso, os valores também foram semelhantes, de 8.319 e $8.493 \mathrm{MJ} \mathrm{mm} \mathrm{ha}^{-1} \mathrm{~h}^{-1}$, respectivamente.

A Figura 3 (B) apresenta o mapa obtido para o fator K, no qual 50,1\% dos solos da RMG apresentam baixo potencial à erodibilidade (classe Baixa), 31,9\% possuem erodibilidade intermediária (classe Média), e 18,1\% dos solos apresentam maior potencial (classe Alta). No que tange aos tipos de solos, há o predomínio de Latossolos, presente em $50,1 \%$ da região, seguido pelos Argissolos, que recobrem 30,5\%, e pelos Cambissolos, com 16,2\%, este último encontra-se bastante antropizados ao sul da região, colaborando com o aumento do nível de susceptibilidade erosiva. Com menor presença na RMG, estão os Gleissolos e Neossolos, recobrindo $1,4 \%$ e $1,8 \%$ da área, 
respectivamente. $\mathrm{O}$ primeiro encontra-se nas margens do ribeirão Meia Ponte, área de atenção, por serem intensamente drenada; os Neossolos de acordo com o uso atual da terra, está, em sua maior parte, preservado quanto à vegetação nativa.

Figura 3 - Mapa de fatores da USLE. (A) Erosividade da chuva; (B) Erodibilidade dos solos; (C) Topografia regional; (D) Uso e manejo da terra.
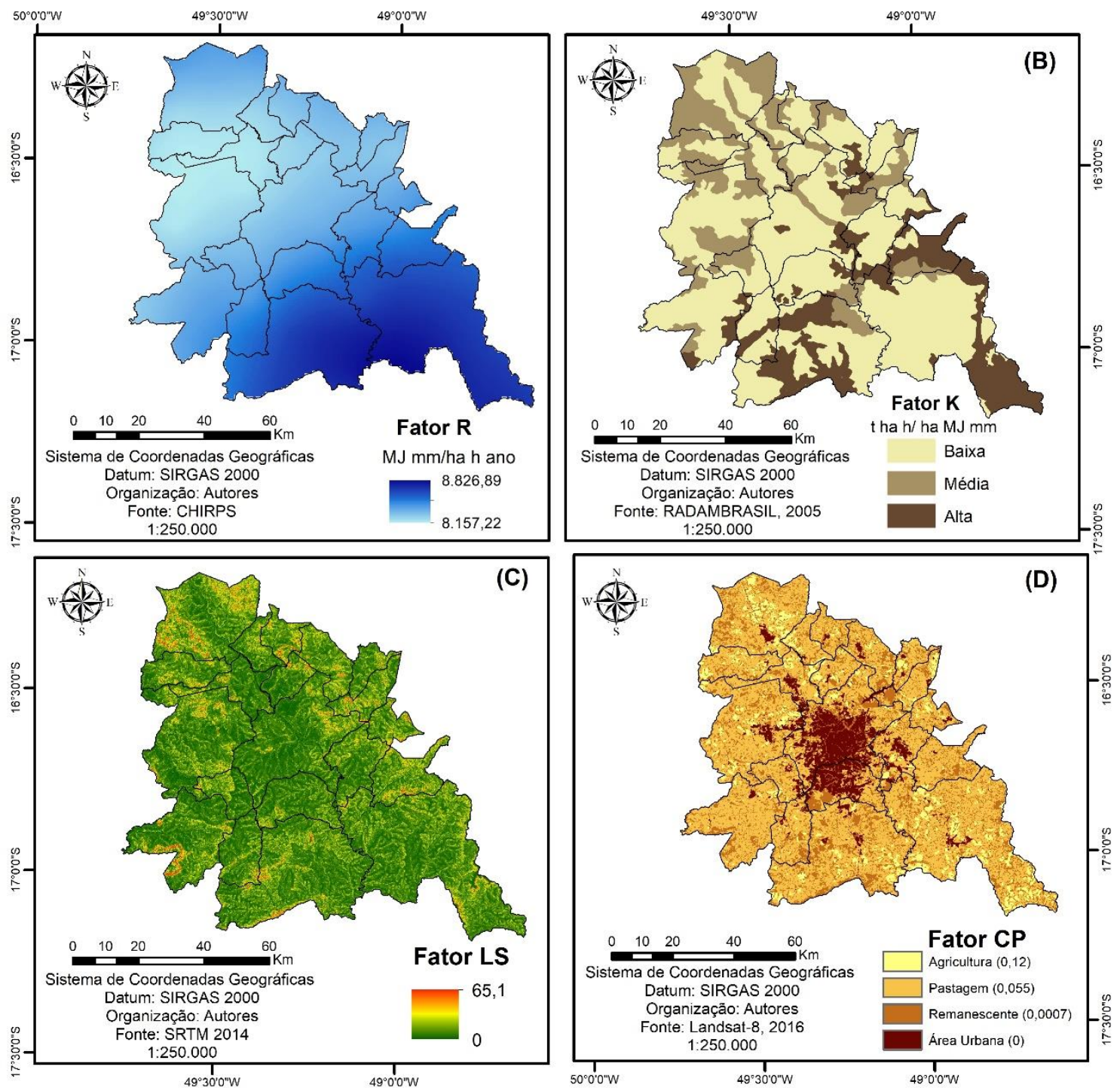

Fonte: Elaborado pelos autores.

O fator topográfico LS (Figura 3C) está associado ao comprimento da vertente e declividade. Nota-se que a maior parte da área possui baixos valores, associados às áreas de planícies. Os locais com declive mais 
acentuado possuem maiores valores, resultando em maior potencial erosivo, como pode ser observado no município de Inhumas (norte), e também em Guapó (sudoeste) da RMG.

$\mathrm{O}$ fator CP (Figura 3D) varia conforme o uso e manejo da terra, sendo os maiores valores associados aos passivos ambientais (áreas convertidas), predispostos a causar maior perda de sedimentos. O valor zero está relacionado as áreas urbanas e aos corpos hídricos, em seguida os menores valores são associados à vegetação remanescente sendo considerada a cobertura mais densa. Essa proteção oferecida aos solos, está relacionada ao entendimento de que quanto mais densa a fitomassa maior será a importância na defesa contra a remoção de sedimentos no processo de escoamento superficial (TOWNSEND et al., 2006).

Os níveis de perda do solo foram analisados de forma qualitativa, devido à escala regional aplicada neste estudo (conforme ressaltado por Stein et al., 1987). Desta forma, os valores foram agrupados em camadas de susceptibilidade erosiva (FAO, 1967), indo de baixa a muito alta.

A espacialização dos fatores permitiu, por meio da quantificação dos pixels, estimar o potencial à erosão, no qual o cenário "Atual” possui 54,56\% da área total da RMG inserida na classe de baixo potencial à erosão laminar. Já no cenário "Pastagem", têm-se 36,44\% da área inserida nesta classe (baixa), seguido pelo cenário "Agricultura”, com 32,49\% da área também na classe de baixo potencial erosivo. Observa-se, portanto, uma influência acentuada do uso do solo nos cenários simulados, pois há uma diminuição das áreas classificadas como "baixa" e, consequentemente, um aumento da perda de solo nas classes alta e muito alta, com 7,69\% e 13,77\% da área inseridos na classe "alta", para os cenários "Pastagem" e "Agricultura", respectivamente (Tabela 1$)$.

Em relação a perda média dos solos, o aumento da pastagem sobre áreas de remanescentes de vegetação, representa um aumento de 51\% na perda dos solos, e a expansão da agricultura sobre a mesma área gera um aumento de $110 \%$ na perda do solo. Em geral, a perda média dos solos permite 
avaliar o aumento dos danos causados ao solo com a expansão da pastagem e da agricultura. No cenário "Atual”, a perda média em toda a região é classificada como baixa, enquanto nos cenários simulados "Pastagem" e "Agricultura", a perda média passa a ser da classe moderada, alertando para o impacto ambiental ocasionado com a mudança do uso da terra na RMG, comprometendo, principalmente, os cursos hidrográficos e nascentes, devido ao aumento do volume de sedimentos.

Tabela 1- Classificação do grau de erosão por cenários na região metropolitana de Goiânia.

\begin{tabular}{|c|c|c|c|c|c|c|c|}
\hline \multirow[b]{2}{*}{ Classes } & \multirow{2}{*}{$\begin{array}{c}\text { Perda } \\
\text { do Solo } \\
\text { t ha- } \\
\text { 1ano-1 }\end{array}$} & \multicolumn{2}{|c|}{ Cenário Atual } & \multicolumn{2}{|c|}{ Cenário Pastagem } & \multicolumn{2}{|c|}{$\begin{array}{c}\text { Cenário } \\
\text { Agricultura }\end{array}$} \\
\hline & & $\begin{array}{l}\text { Área } \\
(\mathbf{k m 2})\end{array}$ & $\%$ & $\begin{array}{c}\text { Área } \\
(\mathbf{k m 2})\end{array}$ & $\%$ & $\begin{array}{c}\text { Área } \\
(\mathbf{k m 2})\end{array}$ & $\%$ \\
\hline Baixa & 0 a 10 & $3.990,70$ & 54,56 & $2.664,86$ & 36,44 & $2.375,99$ & 32,49 \\
\hline Moderada & 10 a 50 & $3.033,44$ & 41,48 & $4.082,85$ & 55,83 & $3.867,85$ & 52,89 \\
\hline Alta & $\begin{array}{l}50 a \\
200\end{array}$ & 288,86 & 3,95 & 562,37 & 7,69 & 1007,00 & 13,77 \\
\hline $\begin{array}{l}\text { Muito } \\
\text { Alta }\end{array}$ & $>200$ & 0,00 & 0,01 & 2,93 & 0,04 & 62,16 & 0,85 \\
\hline Total & - & $7.313,00$ & 100,00 & $7.313,00$ & 100,00 & $7.313,00$ & 100,00 \\
\hline
\end{tabular}

Fonte: Elaborado pelos autores.

A partir da análise do resultado da USLE, o fator A espacializado (Figura 4), verifica-se no cenário “Atual” que, as maiores perdas do solo estão associadas aos locais com declividade mais acentuada, em conjunto aos Cambissolos e com uso da terra destinado a agricultura. No cenário "Pastagem" o aumento da perda do solo relaciona-se às regiões cuja expansão da pastagem se dá sobre os Neossolos, e no cenário "Agricultura" os locais com Cambissolos e também com Neossolos, associados aos maiores declives condicionam as maiores perdas. A extensa área de pastagem já existente na RMG é ressaltada na proximidade dos resultados (apresentados na Figura 4) entre o cenário atual e o cenário pastagem, havendo neste uma perda que cresce para a região central da área. Atualmente na RMG as perdas de solo 
mais expressivas concentram-se nas áreas associadas aos fatores naturais da região que propiciam o aumento de potencialidade erosiva em alguns pontos, como por exemplo, nos relevos mais acidentados no norte da região e extremo sudeste.

Figura 4 - Mapa da distribuição espacial da erosão laminar gerado com os mapas de suscetibilidade erosiva. (A) Cenário Atual; (B) Cenário Pastagem; (C) Cenário Agricultura.

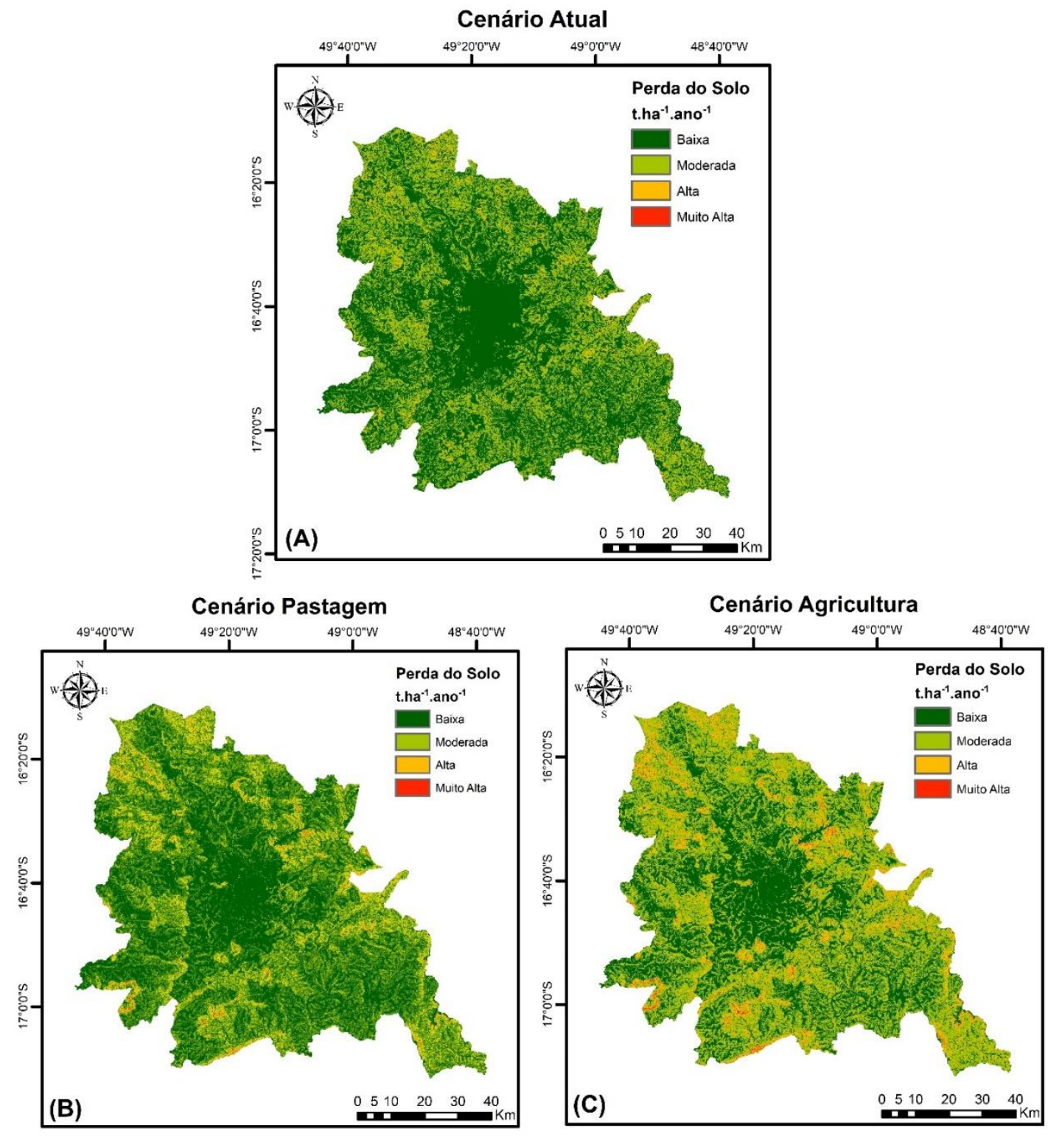

Fonte: Elaborado pelos autores.

Dessa forma, foi possível constatar que a perda do solo em todos os cenários varia conforme a topografia regional, na qual áreas classificadas como de alta susceptibilidade erosiva coincidem com os locais com maiores 
declives, registrando a forte influência do fator LS nos cenários analisados. No entanto, mesmo nessas regiões, as perdas são minimizadas ou acentuadas com a mudança do uso da terra. Isto é, nos cenários "Pastagem" e "Agricultura", a susceptibilidade erosiva encontra-se também relacionada ao fator topográfico, no qual os maiores valores coincidem com a presença da pastagem ou da agricultura em declives mais elevados.

A diferença no controle da erosão laminar entre a pastagem e agricultura pode ser explicada pela baixa, no entanto perene, proteção que a pastagem oferece. Nos solos destinados à agricultura, deve-se levar em consideração os períodos de solo descoberto (entre safras) e o início do brotamento (que apenas garantem o mínimo de recobrimento do solo), deixando-os expostos aos processos naturais de intemperismo, somando-se às especificidades de cada tipo de solo, assim como a alta influência do comprimento e declive da vertente associada.

Em um trabalho sobre simulação de cenários de adequação ambiental os autores, Ferraz et al. (2013) concluíram que a implantação de Reserva Legal, com o planejamento adequado, pode reduzir entre 20 e $70 \%$ as perdas dos solos, e a implantação de Reserva Legal em conjunto com APP tem o potencial de reduzir cerca de 80\% do potencial de ocorrência de erosão laminar em microbacias. Corroborando com as análises realizadas, já que neste trabalho obteve-se o aumento da perda dos solos com a redução dos remanescentes de vegetação.

Segundo Tomazoni et al. (2005), a cobertura vegetal representa uma proteção natural para o solo, sendo que as perdas de solo variam de acordo com a capacidade de proteção que cada cultura oferece. A partir dos cenários apresentados, observa-se que a presença de vegetação remanescente representa uma maior proteção ao solo em contrapartida às pastagens, que acentuam as perdas do solo, ressaltando-se a agricultura como o fator de maior intensificação desse processo.

Avaliando os fatores formadores da USLE e os mapas de susceptibilidade erosiva, infere-se que os locais de maior susceptibilidade 
erosiva (alta e muito alta), no cenário "Atual", devem ser entendidos como prioritários para restauração vegetal. Nos cenários "Pastagem" e "Agricultura", as regiões com perdas de solo elevadas representam áreas impossibilitadas ambientalmente para expansão agropastoril, e requerem a manutenção da vegetação remanescente. As regiões que apresentam uma baixa perda de solo são possíveis locais de expansão da pastagem e/ou agricultura, pois representam menor risco à erosão laminar.

Acerca do fator cobertura e uso da terra no processo de erosão laminar observa-se que diversos estudos afirmam que a cobertura vegetal oferece a melhor proteção aos solos. O adensamento das matas atua na interceptação das águas que atingem os solos com menor velocidade, nesse sentido as folhas também desempenham papel importante, servindo como superfície de retenção da água para posterior evaporação (BERMÚDEZ et al., 1998; TEIXEIRA e MISRA, 1997).

A atividade de pastoreio aumenta a compactação do solo, acentuando o escoamento superficial, resultando em perdas superficiais do solo e então são induzidos os processos de formação de sulcos e o ravinamento (EVANS, 1998; THOMAZ, 2005). Pires et al. (2006) conduziram estudos em áreas de pastagem e observaram que esse uso do solo influenciou de forma considerável a geomorfologia local, apresentando maior susceptibilidade aos processos erosivos, mostrando ainda, maior influência negativa em faixas ao longo de rios, pois o gado retira a vegetação das margens, acentuando a deposição de sedimentos no interior dos riachos. Quanto a velocidade de escoamento superficial da água, as análises de Inácio et al. (2007) em uma área com e sem cobertura de pastagem, indicaram que o escoamento superficial ocorreu entre 0,7 e 1,8 min no solo descoberto, enquanto no solo recoberto por pastagem o tempo varia entre 2,4 e 4,8 $\mathrm{min}$, indicando que as pastagens em comparação com o solo nu oferecem maior proteção quanto ao escoamento superficial.

Os locais com uso do solo reflorestado por eucalipto obtiveram taxas de perdas do solo bem inferiores a tolerância para cada uma das classes de solos 
utilizadas nos estudos realizados por Martins et al. (2010). Em parcelas agrícolas os resíduos de cultura deixados no solo entre um cultivo e outro reduzem o escoamento superficial das águas, atuando contra o impacto direto das águas no solo (COGO et al., 1983). O aumento em 16,2\% de florestas e a redução em 57,5\% de áreas sob agricultura, representou uma redução bruta em 44\% da erosão segundo as análises realizadas, em um período de 19 anos por Caten et al. (2012). Nota-se que a quantidade de água que chega ao solo, depende das características de densidade, grau de desenvolvimento, manejo e tipo de cobertura da terra.

Nesse sentido, ressalta-se a influência da fragmentação florestal na diminuição da cobertura vegetal e consequentemente o aumento da perda dos solos por erosão hídrica. De forma que, a substituição das matas por produtos agricultáveis ocasiona redução da capacidade de infiltração de água no solo. Isso se deve ao modo de ocupação fomentado na expansão da fronteira agrícola no Cerrado, na qual a fragmentação está presente em praticamente todas as etapas, sendo a ocupação efetivada sem as devidas práticas de manejo da terra.

\section{Conclusões}

A mudança de uso e cobertura da terra representa um importante fator na perda do solo, no qual diferentes usos apresentam distintas capacidades de intensificação do potencial erosivo. Nesta pesquisa, observou-se que a substituição da vegetação remanescente por pastagem ou agricultura representa um aumento de perda do solo média de $51 \%$ e $110 \%$, respectivamente para os dois usos. A elevação desses níveis de perda dos solos é crítica, pois alteram as condições naturais da cobertura vegetal e das propriedades dos solos, que se tornam compactados ou expostos às intempéries climáticas.

Verifica-se que, apesar de fortemente fragmentado, os remanescentes de vegetação na RMG ainda garantem a proteção ao solo e, indiretamente, a 
qualidade e disponibilidade de água, por evitar o transporte de sedimentos, o assoreamento e a poluição de canais e reservatórios.

\section{Agradecimentos}

Os autores agradecem à FAPEG (Fundação de Amparo à Pesquisa do Estado de Goiás) pela concessão de bolsa de estudos à primeira autora e também ao CNPq (processo 312229/2014-3) pela bolsa ofertada ao terceiro autor.

\section{Referências}

BAPTISTA, G. M. M. Diagnóstico ambiental de erosão laminar: Modelo Geotecnológico e aplicação. Editora Universa. Brasília, DF. 2003, 140p.

BAZZANO, Marcos Gabriel Peñalva; ELTZ, Flávio Luiz Foletto and CASSOL,

Elemar Antonino. Erosividade, coeficiente de chuva, padrões e período de retorno das chuvas de Quaraí, RS. Rev. Bras. Ciênc. Solo [online]. 2007, vol.31, n.5, pp.1205-1217.

BERMÚDEZ, F.L.; ROMERO, A.D.; FERNANDEZ, J. M.; FERNANDEZ, J.M. Vegetation and soil erosion under a semiarid mediterranean climate: a case study from Murcia (Spain). Geomorphology, v. 24, 1998, pp.51 - 58.

BERTOL, I., ALMEIDA, J. A., TOLERÂNCIA DE PERDA DE SOLO POR EROSÃO PARA OS PRINCIPAIS SOLOS DO ESTADO DE SANTA CATARINA. Revista Brasileira de Ciência do Solo [en linea] 2000, 24 (Sin mes) : Site: $<$ http://www.redalyc.org/articulo.oa?id=180218342018>. Acessado em outubro de 2018.

BERTONI, J.; LOMBARDI NETO, F. Conservação do Solo. $3^{\text {a }}$ edição, Ícone Editora, São Paulo, 1993

BERTONI, J.; LOMBARDI NETO, F. Conservação do solo. $7^{\mathrm{a}}$ edição, Ícone Editora, São Paulo, 2010

BUENO, C. R. P. E STEIN, D. P. Potencial Natural e Antrópico de erosão na região de Brotas, Estado de São Paulo, Acta Scientiarum, Vol. 26, 2005, pp.1-5. 
CARVALHO, JOSÉ R. P. DE.; ASSAD, EDUARDO D. Análise espacial da precipitação pluviométrica no Estado de São Paulo: comparação de métodos de interpolação. Engenharia Agrícola [online]. 2005, vol.25, n.2, $\begin{array}{llll}\text { pp.377-384. } & \text { ISSN }\end{array}$ <http://dx.doi.org/10.1590/S010069162005000200011./>. Acessado em: maio de 2017.

CARVALHO, N.O. Hidrossedimentologia Prática. Rio de Janeiro: CPRM, 1994. $372 \mathrm{p}$.

CARVALHO, N. O. Hidrossedimentologia prática. 2.ed. Rio de Janeiro: Interciência, 2008. 599p

CATEN, A.; DALMOLIN, R.S.D.; PEDRON, F.A.; MENDONÇA-SANTOS, M. de L. Regressões logísticas múltiplas: fatores que influenciam sua aplicação na predição de classes de solos. Revista Brasileira de Ciência do Solo, v.35, 2011b, pp.53-62.

CHAVES, H. M. L. Modelagem matemática da erosão hídrica: passado, presente e futuro. In: ALVAREZ, V. V. H; FONTES, L. E. F.; FONTES, M. P. F. (Eds.). O solo nos grandes domínios morfoclimáticos do Brasil e o desenvolvimento sustentado. Viçosa: Sociedade Brasileira de Ciência do Solo, 1996. pp. $731-750$.

COGO, N.P.; MOLDENHAUER, W.C.; FOSTER, G.R. Soil loss reductions from conservation tillage pratices. Soil Sci. Soc. Am. J., 48, 1983, pp. 368-373.

COLODRO, G.; CARVALHO, M. P.; ROQUE, C. G.; PRADO, R. M . Erosividade da chuva: distribuição e correlação com a precipitação pluviométrica de Teodoro Sampaio (SP). Rev. Bras. Ciênc. Solo, Viçosa, v. 26, n. 3, p. 809-818, Sept. 2002 . Site: <http://www.scielo.br/scielo.php?script=sci_arttext\&pid=S010006832002000300027\&lng=en\&nrm=iso $>$. Acessado em: outubro de 2018.

CONRAD, O.; BECHTEL, B.; BOCK, M.; DIETRICH, H.; FISCHER, E.; GERLITZ, L.; WEHBERG, J.; WICHMANN, V.; BÖHNER, J. (2015): System for Automated Geoscientific Analyses (SAGA) v. 2.1.4, Geosci. Model Dev., 8, 1991-2007, doi:10.5194/gmd-8-1991-2015.

COOK, R. U. \& DOORNKAMP, J. C. Geomorphology in environmental management. Oxford: Clarendon, 1990. 
DEDECEK, R.A. Fatores de erosividade da chuva, enxurrada e perdas de solo sob condições de cerrado. Pesquisa Agropecuária Brasileira, Brasília, v.23, n.12, 1988, pp.1431-1438.

EMBRAPA. Empresa Brasileira de Pesquisa do Agropecuária. Sistema brasileiro de classificação de solos. Rio de Janeiro: Embrapa SPI, 1999. 412p.

EMBRAPA - Empresa Brasileira de Pesquisa Agropecuária. Sistema de informações de solos brasileiros. Rio de Janeiro, 2014. Disponível em: <http://www.bdsolos.cnptia.embrapa.br/>. Acesso em: 16 de dezembro de 2016.

EVANS, R. The erosional impacts of grazing animals. Progress in Physical Geography. 22 (2), 1998, pp. 251- 268.

FAO. La erosión del suelo por el água. Algunas medidas para combatirla en las tierras de cultivo. Cuadernos de fomento agropecuário da Org. De Las Naciones Unidas, Roma: FAO, n.81, 1967, 207 p.

FAO. Wischmeier and Smith Empirical Soil Loss Model (USLE). 1962. Site: <http://www.fao.org/docrep/t1765e/t1765e0e.htm>.Acessado em: agosto de 2017.

FERRAZ, S.F.B DE.; PEREIRA, M.F; PAULA. F.R.DE.; VETTORAZI, C.A.; ALVARES, C.A. Simulação de perdas de solo em função de cenários de adequação ambiental em microbacias agrícolas. Sci. For., Piracicaba, v. 41, n. 98, 2013, pp. 271-282.

FERREIRA, M. E.; MIZIARA, F.; FERREIRA JÚNIOR, L. G.; RIBEIRO, F. L.; FERREIRA, N. C. Ativos ambientais do bioma cerrado: uma análise da cobertura vegetal nativa e sua relação com o preço da terra no estado Goiás. Revista Brasileira de Cartografia, v. 1, n. 61, 2009, pp. 37-50.

FOURNIER, F. Climat et erosion. Paris: Press Universitaires de France, 1960. $201 p$.

GUERRA, A. Experimentos e monitoramentos em erosão dos solos. Revista do Departamento de Geografia, 16, 2011, pp.32-37.

IBGE. Censo demográfico 2010. Indicadores municipais: resultados do universo. Rio de Janeiro: IBGE, 2010. Site: <http://censo2010.ibge.gov.br/apps/atlas/>. Acessado em agosto de 2017, INÁCIO, E. DOS S. B.; CANTALICE, J. R. B.; NACIF, P. G. S.; ARAUJO, Q. R. DE.; BARRETO, A. C. (2007). Quantificação da erosão em pastagem com diferentes 
declives na microbacia do Ribeirão Salomea. Revista Brasileira de Engenharia Agrícola e Ambiental, vol.11, n.4, pp.355-360. 2007. ISSN 1415-4366. Site: <http://dx.doi.org/10.1590/S141543662007000400002>. Acessado em janeiro de 2017.

INMET. Normais Climatológicas 1961 a 1990. INMET. Brasília, 1992.

LIMA, G.S.A; FERREIRA, N.C. RIBEIRO, H.J. NOGUEIRA. S.H.M, Simulação de cenários de perda do solo por erosão laminar na região metropolitana de Goiânia. In: Simpósio Brasileiro de Sensoriamento Remoto (SBSR) 18, 2017, Santos-SP, Brasil Anais... São José dos Campos, INPE, p 3656-3663

LOMBARDI NETO, F.; MOLDENHAUER, W.C. Erosividade da chuva: sua distribuição e relação com as perdas de solo em Campinas (SP). Bragantia, Campinas, 51(2), 1992, pp. 189-196.

MACHADO, R. E.; VETORAZZI, C. A.; XAVIER, A. C. Simulação de cenários alternativos de uso da terra em uma microbacia utilizando técnicas de modelagem e geoprocessamento. Revista Brasileira de Ciência do Solo, Viçosa, v. 27, n. 4, 2003, pp.727-733.

MAGALHÃES.I.A.L; NERY.C.V.M; ZANETTI.S.S; PENA.F.E.R; AVELINO.R.C; SANTOS.A.R. Uso de geotecnologias para estimativa de perda solo e identificação das áreas susceptíveis a erosão laminar na sub-bacia hidrográfica do rio vieira, município de montes claros, MG. Cadernos de Geociências, v. 9, n. 2, novembro 2012.

MARTINS, S.G.; SILVA, M.L.N.; AVANZI, J.C.; CURI, N.; FONSECA, S. Fator cobertura e manejo do solo e perdas de solo e água em cultivo de eucalipto e em Mata Atlântica nos Tabuleiros Costeiros do estado do Espírito Santo. Sci. Forestalis, 38: 2010, pp. 517-526.

MARQUES J.J.G.S.M.; ALVARENGA, R.C.; CURI, N.; SANTANA, D.P.; SILVA, M.L.N. Índices de erosividade da chuva, perdas de solo e fator erodibilidade para dois solos da região dos cerrados - primeira aproximação. Revista Brasileira de Ciência do Solo [online]. 1997, vol.21, n.3, pp.427-434. ISSN 1806-9657. Site: < http://dx.doi.org/10.1590/S010006831997000300011>. Acessado em janeiro de 2017.

MELLO, C.R.; LIMA, J.M.; SILVA, A.M.; MELLO J.M.; OLIVEIRA, M.S. Krigagem e inverso do quadrado da distância para interpolação dos parâmetros da 
equação de chuvas intensas. Revista Brasileira de Ciência do Solo, 27(9), 2003, pp. 925-933.

MELLO, C. R.; SÁ, M. A. C.; CURI, N.; MELLO, J. M.; VIOLA, M. R.; SILVA, A. M. Erosividade mensal e anual da chuva no Estado de Minas Gerais. Pesquisa Agropecuária Brasileira, Brasília, v. 42, n. 4, 2007, pp. 537-545.

MOORE, I. D.; BURCH, G. L. Modeling erosion and depositon: topographic effects. Transaction of the ASAE. v. 20, n. 6, 1986, pp. 1624-1630.

MORAIS, L. F.B.; SILVA, V.; NASCHENVENG, T. M. C.; HARDOIN, P. C.; ALMEIDA, J. E. L.; WEBER, O. L. S.; BOEL, E.; DURIGON, V. Índice EI30 e sua relação com o coeficiente de chuva do sudoeste do Mato Grosso. Revista Brasileira Ciência do Solo, v.15, 1991. pp.339-44.

NASCIMENTO, C. W. A. do; CHAVES, l. de B.. Erosividade e características da chuva correlacionadas com perdas de solo em Alagoinha - PB. Cienc. Rural, Santa Maria , v. 26, n. 3, p. 407-412, Dec. 1996. Site: $<$ http://www.scielo.br/scielo.php?script=sci_arttext\&pid=S0103$84781996000300011 \& \operatorname{lng}=\mathrm{en} \& n r m=$ iso $>$. Acessado em outubro de 2018.

PANACHUKI E.; BERTOL I.; ALVES SOBRINHO T.; OLIVEIRA, PTS, RODRIGUES DBB. Perdas de solo e de água e infiltração de água em Latossolo Vermelho sob sistemas de manejo. R Bras Ci Solo. 2011, pp.1777-86.

PIRES, L. S; SILVA, L. N; CURI, N; LEITE, F.P; BRITO, L.F. Erosão hídrica pósplantio em florestas de eucalipto na região centro-leste de Minas Gerais. Pesquisa Agropecuária Brasileira, v. 41, n. 4, 2006, pp. 687-695.

PRUSKI, F. F. Prejuízos decorrentes da erosão hídrica e tolerância de perdas de solo. In:(ed.). Conservação de solo e água: práticas mecânicas para o controle da erosão hídrica. 2.ed. Viçosa, MG: Ed. UFV, 2009a. pp. 13-23.

RADAMBRASIL. Mapa de solos - Projeto RadamBrasil. Determinação de áreas prioritárias para unidades de preservação - Cons.Imagem/WWF RADAMBRASIL. Agência Ambiental, 2005

RANIERI S.B.L; SPAROVEK G; SOUZA M.P DOURADO NETO D. Aplicação de Índice Comparativo na Avaliação do Risco de degradação das Terras. Revista Brasileira de Ciência do Solo, Volume 22, n. 4, Viçosa - MG, 1998.

SILVA, M.A. Modelagem hidrológica e das perdas de solos: suas relações com a forma do relevo e uso do solo na Bacia do rio Taperoá-PB, 2015. 
Dissertação (Mestrado em Geografia) - Universidade Federal da Paraíba, João Pessoa, 2015.

SILVA, M.L.N.; FREITAS, P.L.; BLANCANEAUX, P.; CURI, N. Índices de erosividade das chuvas da região de Goiânia, GO. Pesquisa Agropecuária Brasileira, v. 32, 1997, pp. 977-985.

STEIN, D. P.; DONZELLI, P. L.; GIMENEZ, A. F. PONÇANO, W. L. LOMBARDI NETO, F. Potencial de erosão laminar, natural e antrópico na Bacia do PeixeParanapanema. Anais.. do IV Simpósio Nacional de Controle de Erosão. Marília, SP, 1987. P. 105-135.

TEIXEIRA, P.C.; R.K. MISRA. Erosion and sediment characteristics of cultivated forest soils as affected by the mechanical stability of aggregates. Catenav. 30, 1997, pp. 199-134.

TEZA, C. T. V.; BAPTISTA, G. M. DE M. Identificação do fenômeno ilhas urbanas de calor por meio de dados ASTER on demand 8 - Kinetic Temperature (III): metrópoles brasileiras. In: Anais do Simpósio Brasileiro de Sensoriamento Remoto, 12, Goiânia: INPE, 2005. pp. 3911-3918.

THOMAZ, E. L. Processos hidrogeomorfológicos e o uso da terra em ambiente subtropical - Guarapuava - PR. São Paulo, f. Tese (Doutorado em Ciência, área Geografia Física) - Faculdade de Filosofia Letras e Ciências Humanas, Universidade de São Paulo, 2005.

TOMAZONI, J.C.; MANTOVANI, L.E.; BITTENCOURT, A.V.L.; Rosa Filho, E.F. da. A sistematização dos fatores da Eups em Sig para quantificação da erosão laminar na bacia do rio Anta Gorda (PR). Estudos Geográficos, Rio Claro, v.3, n.1, 2005, pp.1-21.

TOWNSEND, C.R.; BEGON, M.; HARPER, J.L. Fundamentos em ecologia. 2. ed. Porto Alegre, Artmed, 2006. 592 p. Site: $<$ http://www.scielo.br/scieloOrg/php/similar.php?lang=en\&text=\%20Fundame ntos\%20em\%20ecologia >. Acessado em agosto de 2017.

USGS EROS Data Center. Shuttle Radar Topography Mission, 2014. Site: <https://earthexplorer.usgs.gov>. Acessado em março de 2017.

WANDERLEY, H. S.; AMORIM, R. S. C.; CARVALHO, F. O. Variabilidade espacial e preenchimento de falhas de dados pluviométricos para o estado de Alagoas. Revista Brasileira de Meteorologia, v.27, 2012, pp. 347-354. 
WISCHMEIER, W. H. \& SMITH, D. D. Predicting a rainfall erosion losses - a

guide to conservation planning. (Agricultural Hándbook $\mathrm{n}^{0}$ 573). Washington: USDA/ARS, 1978. 58 p. 